\title{
The Human Mandible and the Origins of Speech
}

\author{
David J. Daegling \\ Department of Anthropology, University of Florida, Gainesville, FL 32611-7305, USA \\ Correspondence should be addressed to David J. Daegling, daegling@ufl.edu
}

Received 1 November 2011; Accepted 6 February 2012

Academic Editor: Emiliano Bruner

Copyright (C) 2012 David J. Daegling. This is an open access article distributed under the Creative Commons Attribution License, which permits unrestricted use, distribution, and reproduction in any medium, provided the original work is properly cited.

\begin{abstract}
Among the unique traits of human mandibles is the finding of relatively greater utilization of cortical bone with respect to other hominoids. The functional significance of this trait is not plausibly linked to masticatory demands given the diminution of the masticatory musculature in human evolution and the behavioral universal of extraoral food preparation in recent humans. Similarly, the presence of more mandibular bone is not a correlated effect of systemic skeletal robusticity, since gracilization of the skeleton is a feature diagnostic of modern humans. The mandibular symphysis in modern humans is manifested as the chin, and it is here where cortical bone hypertrophy is most pronounced. The potential covariation between the expression of the chin and bone hypertrophy is explored in an attempt to clarify their respective biomechanical roles. Current developments in skeletal biomechanics implicate low magnitude, high frequency strains in bone hypertrophy. The physiology of speech production likely produces strains in mandibular bone of greater frequency and lesser magnitude than those associated with mastication. Consequently, language acquisition plausibly accounts for cortical hypertrophy in modern human mandibles. Its role in the evolution and development of the chin is less clear.
\end{abstract}

\section{Introduction}

No consensus exists that there is a diagnostic anatomical indicator for articulate speech in human evolution. This absence of success cannot be attributed to a lack of effort in identifying suitable candidates [1]. Whether unique aspects of human hyoid, basicranial, or hypoglossal canal morphology indicate the capacity for spoken language is contested [2-6]. Additionally, the appearance of the human chin has been suggested to indicate the advent of articulate speech [7-9], but no empirical data provide unambiguous linkage of the physiology of speech with variation in mandibular symphyseal morphology [10-13].

The human mandible is morphologically distinct from other primates both in terms of its proportions and specific anatomical features [11]. Anterior corpus morphology in humans is truly unique among anthropoids, in that the lingual transverse tori and genial pit are absent, and the labial surface is characterized by a basal swelling (the "chin") with several definable features idiosyncratic to human jaws (e.g., trigonum mentale, and incurvatio mandibulae anterior). Even though the chin is recognized as diagnostic of our species, its evolutionary and functional significance remain incompletely understood $[14,15]$.

Despite the ease with which it can be recognized, the chin has nevertheless been the focus of considerable debate as to its essence [16]. A consensus of definition is elusive, and no attempt to resolve it will be made here; instead, the "chin" in this paper refers to an anterior basal swelling of the mandibular symphysis. In this sense, it "requires" anterior incurvatios for its expression. It is also assumed here that, although cortical hypertrophy and the expression of the chin both delineate humans from other extant hominoids, these features can be considered logically separate in terms of their adaptive or evolutionary significance. This assumption underlies an analytical strategy where the causes and effects of hypertrophy can be considered independently of the expression of the chin. In fact, the features are potentially part of a single functional complex. In the discussion that follows, "symphysis" refers to the midline of the mandible (i.e., the section transected by the midsagittal plane), "corpus" refers to the tooth-bearing portion of the jaw, and "anterior corpus" is the region of the mandible anterior or rostral to the canines. 


\section{Cortical Bone Hypertrophy in the Human Mandible}

Beyond the chin, another feature of human mandibular morphology that distinguishes us from other extant hominoids is the relative amount of cortical bone that is utilized in the corpus [17]. Relative to mandibular length, human mandibles have relatively more bone throughout the corpus than Great Apes (Figure 1). In addition, relative to subperiosteal area, human mandibles incorporate relatively more bone into the symphyseal region of the anterior corpus (Figure 2).

The unusually dense packing of bone in the anterior corpus of human jaws does not appear to be explicable as an effect of allometric scaling (Figure 3). Whether evaluated against mandibular length (a general-purpose biomechanical size proxy owing to its being proportional to bending moment arms that act during mastication [18-22]) or total subperiosteal area (Figure 4), recent humans display more bone than expected given the scaling relationships of hominoids as a whole. Human cortical hypertrophy is thus not explicable as the predicted outcome of bone mass in a mandible of its particular dimensions.

At least three functional explanations serve as competing hypotheses to explain cortical hypertrophy in the modern human mandible. These hypotheses are (1) bone mass is related to shifting masticatory demands in recent human evolution, (2) bone mass in the mandible is correlated with factors influencing cortical bone metabolism systemically, and (3) bone mass is related to the unique human capacity for articulate speech. Each of these hypotheses is critically examined presently.

2.1. Shifting Masticatory Demands. Two important events in human evolution are instrumental to understanding recent changes in masticatory biomechanics. One is that the muscles of mastication became smaller relatively early in the evolution of Homo, although the cause and timing of this event is disputed [24, 25]. What is likely is that over the course of human evolution, the ability to produce large masticatory forces was compromised. The second event was the advent of extraoral food processing, which today represents a ubiquitous feature of human ecology [26]. A certain effect of this technology, whenever and however it occurred, is that the production of large occlusal forces becomes progressively more unnecessary and less selectively important. Whatever the chain of causality between reduced musculature and food processing technology may have been, the biomechanical effects are straightforward: the genus Homo evolved a masticatory apparatus less capable of producing large occlusal forces with no apparent cost to fitness.

If one makes the reasonable assumption that the effect, if not the intent, of extraoral food processing was to make the bolus less resistant to breakdown (see [27] for explanation of the material parameters involved), then the recent human masticatory environment is relatively benign in terms of the muscular and biting forces that are required. Whether this translates to a relatively benign stress environment depends on what changes in mandibular size and shape have occurred. Certainly, the shortened mandible of modern humans predisposes the corpus to reduced stress in terms of bending alone, and despite the reduction in corpus dimensions modern humans appear to be remarkably "overdesigned" in the postcanine corpus, having larger dimensions than needed to maintain stresses within a sufficient margin of safety [17]. It is in the anterior corpus where humans display the greatest hypertrophy of cortical bone mass (Figure 5), and since this is where the difference between ape and human corpus dimensions are strikingly divergent, this hypertrophy could plausibly be associated with a functional response for reducing masticatory stresses. This explanation is undermined given that adductor force in humans is probably well below that utilized by Great Apes. That is, humans likely do not produce the forces necessary to create mandibular stresses equivalent to those in Great Apes given the amount of bone we utilize. Comparative data on muscle force are hard to come by, but healthy human subjects may typically produce bite forces in the range of 350-1235 N [28-32], and theoretical analysis suggests that forces between 700 and $1300 \mathrm{~N}$ are possible $[33,34]$. By contrast, gorillas and chimpanzee bite force capability may exceed $1500 \mathrm{~N}$ [34], and orangutans are probably capable of approaching $2000 \mathrm{~N}$ of occlusal force [35]. The higher estimates for humans suggest peak occlusal forces approaching those of chimpanzees but with a more efficient conversion of adductor force into useful bite force. The same craniofacial geometry that leads to this greater efficiency in humans also reduces the magnitude of bending moments acting on the mandible, but whether this implies equivalent or reduced stresses in humans relative to other hominoids depends upon which estimate of bite force is most reflective of human masticatory behavior. Under an assumption that extraoral food processing is ubiquitous for anatomically modern Homo sapiens [26], the theoretically highest occlusal forces that humans produce are unlikely to be routine. Since adductor forces in humans are reduced relative to large-bodied hominoids, it is thus reasonable to hypothesize that humans experience relatively low levels of bending stress during mastication [17].

In addition to bending, axial torsion of the corpus is a likely source of stress in human mandibles. The prediction of twisting stress magnitudes, however, is complicated by the fact that it is difficult to estimate the moment arms in twisting from simple consideration of skull morphology. In absolute terms, torsional strength in humans is reduced relative to Great Apes (Table 1), but when scaled to proxies of available adductor force, Homo would appear to experience less stress compared to chimpanzees. Given an assumption that twisting moments in humans are no larger than those in Great Apes, then it is reasonable to conclude that twisting stresses are equivalent, if not lower, in humans relative to apes.

While confirmatory data are currently lacking, the preceding discussion supports the inference that the bending and twisting moments produced by humans do not produce the types of stresses that would account for the amount of 


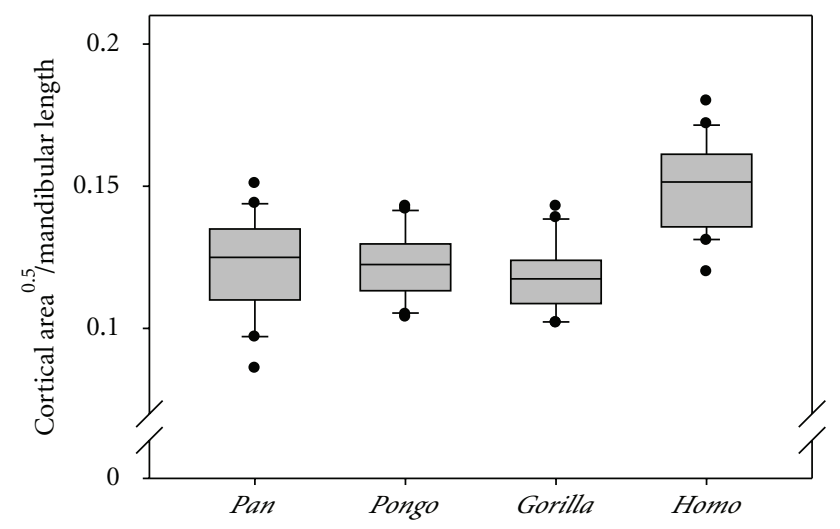

FIGURE 1: The ratio of mandibular bone area $\left(\mathrm{mm}^{2}\right.$ raised to the 0.5 power) in midsagittal section to mandibular length $(\mathrm{mm}$, measured from infradentale to the intersection of the midsagittal plane with the gonion-gonion chord)) in samples of adult great apes and humans $(N=10$ males and females for each taxon $)$. 25th and 75th percentiles (box), median (line), 10th and 90th percentiles (whiskers) and outliers are shown. For this index, ANOVA is significant $(P<0.001)$, and unplanned comparisons show no difference among the apes while humans differ from each ape species at $P<0.05$. This finding of significantly greater amount of bone given jaw length in humans applies throughout the corpus [17].

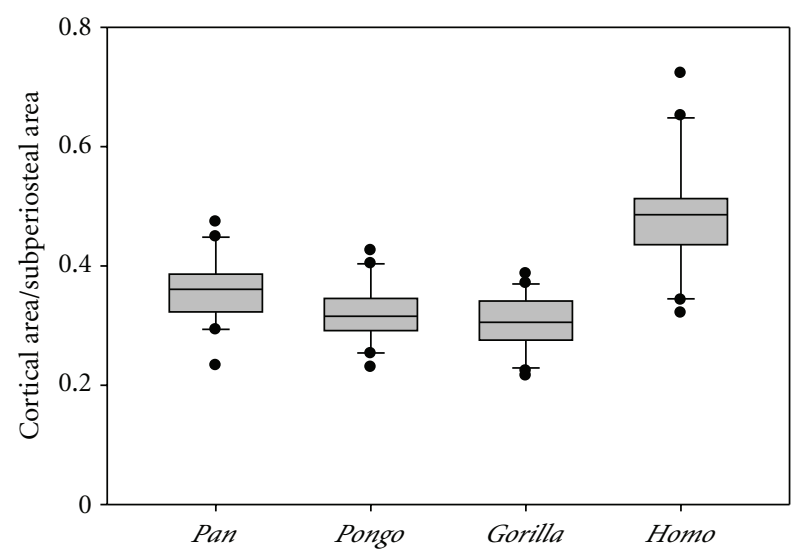

FIgure 2: Mandibular bone area $\left(\mathrm{mm}^{2}\right)$ in midsagittal section as a fraction of total subperiosteal area in samples of adult great apes and humans ( $N=10$ males and females for each taxon). 25th and 75th percentiles (box), median (line), 10th and 90th percentiles (whiskers) and outliers are shown. For this index, ANOVA is significant $(P<0.001)$, and unplanned comparisons show no difference among the apes while humans differ from each ape species at $P<0.05$. This finding of significantly greater bone packing in humans is most pronounced in the anterior corpus [17].

bone found in human jaws. Since humans may not experience stress magnitudes equivalent to other anthropoids, then the hypothesis that cortical hypertrophy in human mandibles represents a structural response to masticatory forces is not compelling. This argument assumes that human bone is responsive to mechanical stress in the same manner as bone tissue in nonhuman primates.

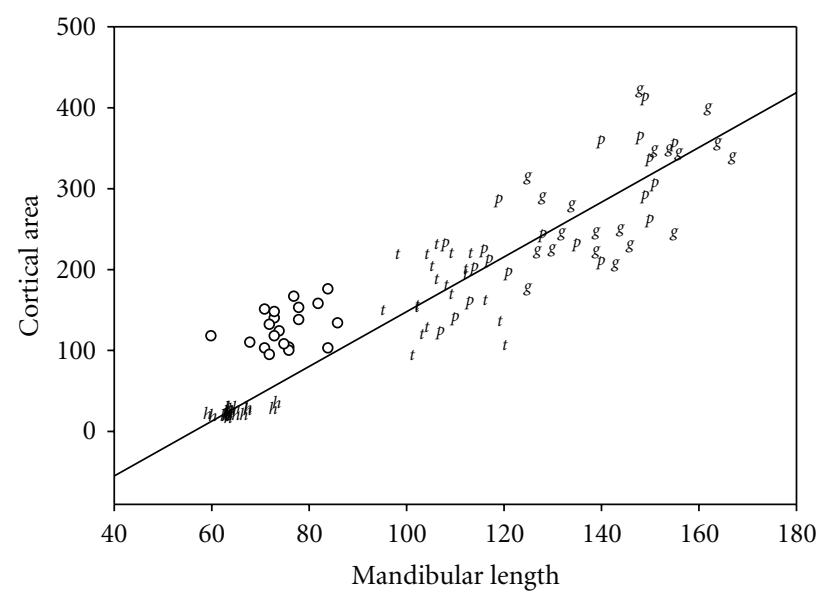

FIgURE 3: Regression of cortical area in midsagittal section on mandibular length $(r=0.93)$ for an adult sample of 100 hominoid mandibles $(N=10$ males and females of Pan troglodytes $[t]$, Pongo pygmaeus [p], Gorilla gorilla [g], Homo [open circles], Hylobates lar and agilis [h]) [23]. The modern human sample (open circles) is superimposed on the hominoid regression. Human mandibles possess more bone than expected based on scaling relationships among all hominoids, based on a $G$-test for the random distribution of residuals above and below the regression line $(P<0.001)$.

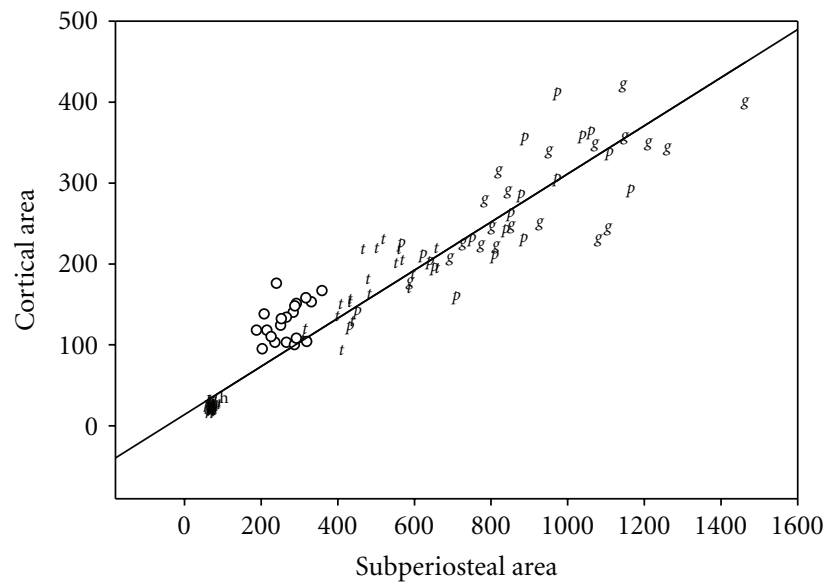

FIgURE 4: Regression of cortical area in midsagittal section on subperisoteal area $(r=0.95)$ for a sample of 100 hominoid mandibles $(N=10$ males and females of Pan troglodytes [ $t]$, Pongo pygmaeus [p], Gorilla gorilla [g], Homo [open circles], Hylobates lar and agilis $[h])$ [23]. The modern human sample (open circles) is superimposed on the hominoid regression. Human mandibles possess more bone than expected based on scaling relationships among all hominoids, based on a $G$-test for the random distribution of residuals above and below the regression line $(P<0.001)$.

The premise of a functional linkage between mandibular bone mass and geometry on the one hand, and masticatory forces on the other, is merely a specific invocation of the general principle that the developmental loading environment governs bone modeling [36, 37]. Alterations to bone mass and geometry are the outcome of modeling activity (particularly during growth), while bone remodeling is the 


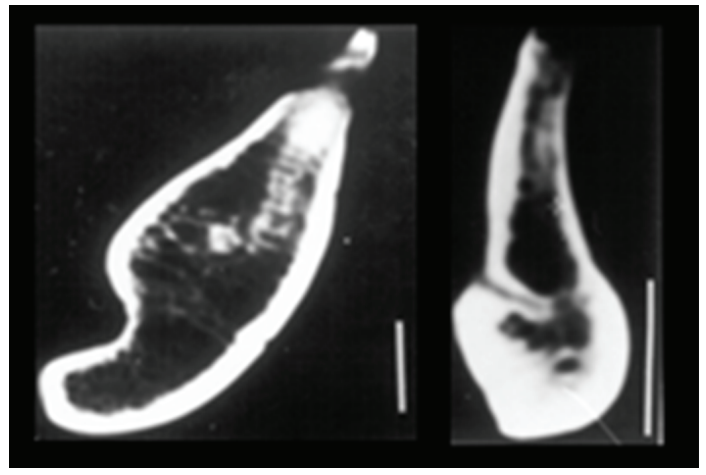

Figure 5: Cortical bone contours in midline sections of gorilla (left) and human (right) mandibles. Labial aspect is to the right. Scale bar is $10 \mathrm{~mm}$. In humans, on average, cortical bone accounts for $49 \%$ of the overall area enclosed by the periosteal (outer) boundary of the midline section; in gorillas the average fraction of the total area taken up by cortical bone is about $30 \%$. Because the overall size of the symphysis is significantly smaller than those of great apes, the added bone in the human symphysis does not match the absolute strength in great ape mandibles. Scaled to mandibular length (an appropriate biomechanical size proxy), humans have on average, relatively stronger symphyses [17]. This does not account for the reduced adductor and biting forces that humans produce. Accounting for these factors and the fact that our masticatory demands are reduced due to our practice of extroral food processing, human jaws appear to be much stronger than necessary given the mass and distribution of cortical bone.

TABLE 1: Torsional strength of hominoid mandibles.

\begin{tabular}{lcccc}
\hline Taxon & Mean & Standard error & Range & $T / K$ ratio \\
\hline Homo & 542 & 37 & $292-1072$ & 1.6 \\
Pan & 556 & 40 & $314-896$ & 2.4 \\
Pongo & 879 & 68 & $490-1456$ & 1.1 \\
Gorilla & 1729 & 102 & $1198-2808$ & 0.9 \\
\hline
\end{tabular}

$N=20$ (10 males, 10 females) for each taxon. Means, standard errors and ranges are for a thin-tube model for torsional strength $\left(K\right.$, units in $\left.\mathrm{mm}^{3}\right)$, which determines strength as a function of area and minimum wall thickness $[17,44]$. Nonparametric ANOVA for mean values of $K$ is significant at $P<0.001$. Post hoc tests reveal that all pairwise comparisons are significant with the exception of Homo versus $\mathrm{Pan}(P>0.05)$. The $T / K$ ratio estimates torsional shear stress, where $T$ is the applied twisting moment. Since the twisting moment arm is difficult to estimate from skeletal material, the moment arm is assumed constant (1.0, arbitrary units), and the applied force is considered to be the summed estimated forces of the jaw adductors from reference [34].

more dominant metabolic activity in adulthood [38]. It is well established that dynamic rather than static loading is implicated in bone metabolic activity [39]. Some models of bone modeling emphasize strain magnitude as important $[40,41]$, while experimental data is accumulating that implicates strain frequency as an important stimulus for bone formation $[42,43]$. The interaction of these variables is also an important consideration.

If strain magnitude represents the stimulus for bone formation or resorption, then conceptually there exists some stress or strain interval that is "ideal" in that it is the target of metabolic activity. On the other hand, if highfrequency loads, irrespective of magnitude, are associated with increased modeling or remodeling activity, then the metabolic response is less clearly directed to a particular range of stress or strain. There is, however, an abundance of evidence that alteration of load history in terms of frequency, magnitude, or both can engender significant changes in bone mass and/or geometry $[41,45,46]$. It is in this light that comparative differences in bone size and shape are interpreted in a biomechanical framework. In the present context, changes in bone mass (cortical packing) or geometry (the contours of the chin) which have culminated in modern human mandibular morphology are conceptualized as the result of evolutionary changes in patterns of stress. Comparative investigations have assumed that changes in relative stress magnitude, rather than frequency, are more important for explaining the form of the human mandible $[11,14,47]$.

2.2. Systemic Cortical Robusticity. That bone mass is sensitive to systemic effects of hormonal factors and disease is well established. More provocative in the context of human evolution is that the activity levels that influence certain regions of the skeleton may produce systemic effects which mimic functional adaptation to stress on a local scale. The most explicit articulation of this hypothesis proposes that cranial bone thickness may represent an effect of generalized locomotor or other activity rather than being specifically responsive to one or more cranial functions [48]. In its most distilled form, the hypothesis posits that bone adaptation to local stress spills over beyond an affected region and produces similar effects throughout the skeleton. Beyond Lieberman's limited experimental data, there is scarce empirical support for this idea, although the absence of support is in some part due to a paucity of experimental designs that specifically evaluate the hypothesis.

Both Asian Homo erectus and Homo neanderthalensis are distinguished from Homo sapiens in terms of skeletal robusticity, especially in the cranium, and indeed recent human evolution is associated with skeletal gracilization in the context of shift in foraging strategy [49]. Diminution of the mandible is but one feature of this trend $[50,51]$. Robusticity can be defined in various ways beyond size, however, including the absolute and relative thickness of the bones under consideration. In the modern human mandible, the cortical bone is unusually thick by hominoid standards even though corpus size itself is considerably reduced (Figure 5). By this criterion of thick cortices, the modern human mandible is "robust" in the same way as, for example, Neanderthal long bones. Yet this phenomenon of thick mandibular bone is not part of a general skeletal feature in modern humans because the remainder of the craniofacial skeleton is not characterized by cortical hypertrophy. Consequently, whatever factors underlie systemic skeletal robusticity, the human mandible cannot be explained by their effects as the packing of bone in the jaw is atypical of the remainder of the skeleton. 
2.3. Bone Mass in the Mandible Relates to Speech. The idea that relatively thick cortical bone in the human mandible could be functionally related to speech is nonintuitive in that phoneme articulation is a low-stress activity compared to mastication. That is, if mastication of unprepared, uncooked food among apes does not produce cortical hypertrophy in their mandibles, why should we expect speaking to be causal in producing thick bone in ours? In fact, activities such as talking have been suggested to be a critical consideration for understanding the relationship of the functional linkage of physiological activity and bone morphology [52]. Accumulating evidence suggests that high-frequency, lowamplitude strains strongly influence bone metabolic activity $[42,52,53]$, such that introduction of novel loading regimes involving low magnitude strains ( $5 \mu \varepsilon$ or below) at high frequencies $(\sim 30 \mathrm{~Hz})$ is sufficient to produce significant increases in trabecular density and number, bone volume fraction, and bone formation rate. These data suggest strain frequency has an important role in the determination of bone structure. While most work in this area suggests that cancellous bone formation is most dramatically affected by imposition of low-magnitude, high-frequency loads, this type of loading regime has produced increases in cortical bone mass in human subjects [54].

The critical question is whether speech produces the kind of loading environment that is conducive to sustained bone formation in the human mandible, and if talking is to be uniquely implicated in bone hypertrophy, the loads produced must be distinct from those encountered in masticatory activity. Human language does involve utilization of the muscles of mastication to produce the mandibular movements involved in speech production [55], but at daily cycle numbers which may routinely exceed those associated with feeding. The complex movements of the tongue required for phoneme production likely involve continuous activity in suprahyoid muscles with mandibular insertions, most notably Genioglossus $[56,57]$. Because the mandible is moved without resistance during speaking and the glossal musculature is relatively diminutive with respect to the mass of the mandible, speech would appear to be capable of imposing low-magnitude stresses at relatively high frequency.

Chewing cycle frequency in humans averages about $1.4 \mathrm{~Hz}$ [58], with a range of 1.2-1.7 for masticating foods of various hardness [59]. Speech rates will obviously be variable, and one concern is what should count as a speech "cycle" in the intended biomechanical context. In a study contrasting masticatory movements with an artificial speech task, duration of opening and closing movements was significantly lessened in speech [60], supporting the idea that speech "frequency" is typically greater than masticatory frequency. Speech rates have been quantified to 3.5-6.5 syllables/s [61]) and 6.7 morae/s [62]. From polysyllabic English word durations of native and nonnative speakers, rates between 4.5-5.0 syllables/s are observed [63]. Investigation of speaking rate over 5,000 utterances (over four hours of data) suggest similar rates but underscore the variability intrinsic to conversational speech in that a range of values from over 1 to nearly 10 syllables/second can be observed [64]. Assuming that the transition between syllables involves mandibular movements and altered recruitment of the masticatory, suprahyoid, and Genioglossus muscles, these observed rates may provide a first approximation of the loading frequency of the mandible during spoken language. Given this assumption, the loading frequency during speech may be from 3-5 times greater than those of mastication.

Mandibular bone strain in mastication or speech is not known from human subjects. Theoretical modeling studies suggest that the difference in strain magnitude between mastication and speech may exceed two orders of magnitude $[65,66]$. The anatomical relationships of the masticatory and suprahyoid musculature to the maxilla and mandible suggest that the low-amplitude, high-frequency loads associated with speech will primarily affect mandibular rather than maxillary bone. There are two reasons to suspect that this is true. First, of the extrinsic tongue muscles, Genioglossus originates on the mandible, and the others have no direct attachment to the maxilla (Hyoglossus, Styloglossus, and Palatoglossus). Second, the opening and closing movements of the mandible involve subtle but measurable changes in the width of the mandibular arcade owing to the masticatory muscles acting upon it to the exclusion of the maxilla. The lines of action of the Masseter and Temporalis include a lateral component, and those of the lateral and medial pterygoids include a medial component (though their primary actions differ, in that only Lateral Pterygoid is involved in jaw opening [67]). These small components produce transverse bending during jaw opening and closing in nonhuman primates [68].

If the hypothesis that bone hypertrophy in the human mandible is functionally related to speech is true, then it must explain why this hypertrophy is most pronounced in the anterior corpus, whereas the distribution of bone is less distinct from other hominoids in the postcanine corpus. There are two effects of language use, one local and one remote, which can be postulated to explain this. First, both Genioglossus and the anterior belly of the Digastric insert on the lingual inferior symphysis: the former muscle is more or less constantly active in speech, and the latter is used for positioning the jaw during certain speech tasks [69]. The forces exerted by these muscles on the symphyseal bone are dynamic and low and probably have negligible impact on the strain field in the postcanine region. Second, the actions of the masticatory muscles in positioning the mandible during speech tasks will produce small transverse bending moments that will have their largest effects in the anterior rather than the posterior corpus.

The preceding points should not be taken to mean that the biomechanical impact of speech is confined to the anterior corpus. Other muscles important in speech production (e.g., Mylohyoid) probably have local effects at their insertions, although the overall geometry of the mandible makes it unlikely that anything other than the muscles of mastication produce significant bending or twisting of the jaw during speech. Any such moments induced in speech will have global effects in the sense that they influence the strain field all along the corpus, but these effects will not be uniform. One of the most striking features of the human mandible is that given overall size, there is more 
bone than expected everywhere in the corpus [17]. This is consistent with the observation that the masticatory muscles are intimately involved with speech, because their actions will have stress effects throughout the mandible. Based on anatomical relationships and biomechanical principles, strains arising from speech activity will likely be highest in the region of the chin-that uniquely human trait which allows us to identify ourselves in the fossil record. This observation then prompts the question of whether the chin itself is related to the acquisition of spoken language.

\section{Revisiting the Chin Problem}

The idea that the human chin is the product of language is not new $[8,9]$, and the hypothesis is still being explored today [7]. It is an attractive hypothesis in that it ties together two unique human attributes in a single functional package. The evolutionary significance of the chin has been pondered for over a century (reviewed in refs. $[14,16]$ ), but the recent literature on the subject is divided among essentially four points of view: (1) the chin represents an adaptation to a novel and unique biomechanical environment $[14,70]$; (2) the chin is the result of sexual selection $[71,72]$; (3) the chin is but a structural artifact having no important biomechanical function [73]; (4) the chin is a structural response to the physiology of speech [7].

The cortical hypertrophy of the anterior corpus has no necessary connection to the presence and form of the chin; however, it is theoretically possible that the distribution of bone and the geometry of the region are part of a single functional complex. It is therefore prudent to evaluate whether by explaining the bone packing that is apparently unique to humans, the function (or lack thereof) of the chin might also be revealed.

\subsection{The Chin Results from Masticatory Biomechanical Factors.} I argued previously that the chin was the result of changes in human jaw proportions which lessened the impact of wishboning strains but did not mitigate another important source of masticatory stress, coronal bending of the anterior corpus by twisting of the postcanine corpora [14]. The validity of this hypothesis had certain predictable outcomes. First, the emergence of the chin in the genus Homo would be closely tied to changes in jaw size and architecture. Subsequent investigation has shown that support for this is equivocal [15]. Implicit also is the assumption that having a discernible chin confers a mechanical advantage under the critical load (coronal bending) than a mandible lacking this feature. The results of recent finite-element modeling studies $[74,75]$ are in conflict on this point. It is thus unclear whether, once size is controlled, the morphology of the chin confers a mechanical advantage over a hypothetical "nonchinned" morphology. Certainly, the chin does serve to stiffen the anterior corpus, but whether it must therefore represent an adaptation to shifting masticatory demands remains an open question [74].

If the chin is a structural response to masticatory function, there are predictions that follow in terms of scaling of its size relative to moment arm and force proxies. Because this type of comparison is necessarily intraspecific, the analysis represents an extreme case of narrow allometry, and high correlations are not expected even if a significant bivariate relationship is observed. Figures 6, 7, and 8 relate chin size to those variables which are expected to covary with it if mitigation of masticatory stress is important in modern humans. In each case, this covariation is sufficiently tenuous that we may reasonably suppose that the relationship is weak if it exists at all. In the case of significant regression of chin size on bicanine breadth, this does correspond to the idea that coronal bending is the critical load influencing the human anterior corpus [14], but as chin size is explained by a mere $4 \%$ of the variance in bicanine breadth, this apparent relationship may equally plausibly be interpreted as a correlated effect of somatic size [76]. These observations, in addition to the foregoing point that both force and bending moment production are probably highly reduced in recent humans, weaken the hypothesis that the human chin is primarily a response to altered masticatory biomechanics.

3.2. The Chin Results from Sexual Selection. The dimorphism of the human chin continues to fuel speculation that it is maintained as an object of sexual selection [71], not an unreasonable view considering its sex-specific characteristics [77]. A critical issue is how variation in the bony form of the chin influences its appearance in terms of physiognomy. That is, the chin may be important in its role in shaping patterns of symmetry in the human face rather than in the details of its configuration [72]. In juxtaposing the sexual selection hypothesis against the masticatory stress hypothesis, if the bony conformation of the chin is the result of sexual selection to the exclusion of masticatory or other biomechanical stress, males and females might be expected to display divergent morphologies relative to measures of size and shape. Whether the salience of the bony chin in profile (Figure 9) or its shape and size relative to mandibular size (Figures 10 and 11) is considered, there appears to be no consistent difference between the sexes in midsagittal section, which is the appropriate perspective in evaluating biomechanical effects. Similarly, there is no indication that there are significant sex differences in humans with respect to bone structural properties [16]. If the chin is the product of sexual selection, it has not resulted in obvious differences in biomechanical performance between males and females, despite the fact that postadolescent growth of the mandible is distinct between males and females [78]. The hypothesis of sexual selection, however, does not easily lend itself to explanations of bone hypertrophy [14].

3.3. The Chin Is a Structural Artifact. The chin was featured as an example of a nonadaptive character in Gould and Lewontin's [80] critique of adaptationism. In that paper, the chin was described as the result of interacting growth fields without any necessary functional utility; in essence, a necessary but (in itself) selectively unimportant artifact of development. While the possibility cannot be denied, as explanation this is unsatisfactory since there is no skeletal 


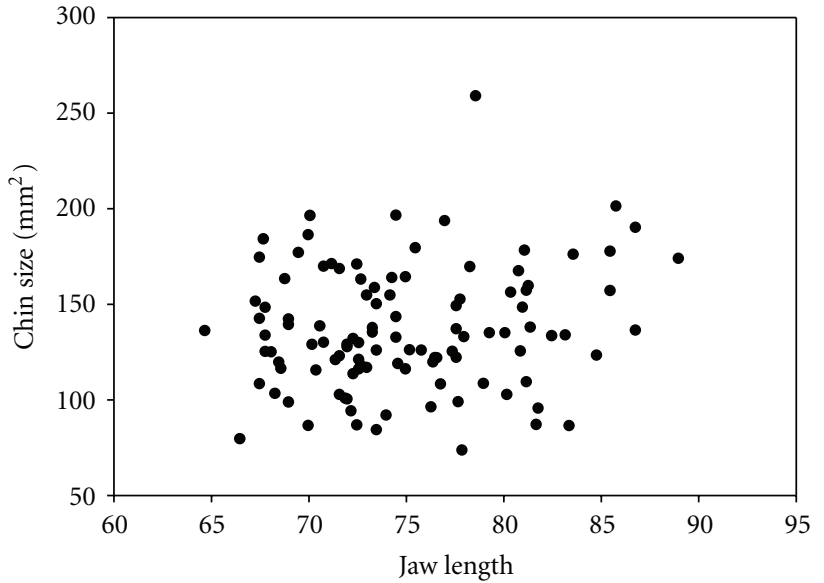

Figure 6: Chin size relative to mandibular length for a mixsexed sample of adult modern humans from the Tigara $(N=$ $57)$ and El Hesa $(N=51)$ collections housed at the American Museum of Natural History. Mandibular length $(\mathrm{mm})$ represents a general biomechanical size proxy, such that if forceful mastication is important in determining corpus size, the expectation is for positive correlation between the variables. Regression is nonsignificant $(P=$ 0.12 ) indicating an absence of such a relationship. Chin size (units in $\mathrm{mm}^{2}$ ) is determined as a simple product of midsagittal height and chin thickness at the tuber symphyseos; that is, there is no accounting for subperiosteal bone area in these measurements. The Egyptian El Hesa sample dates between 200-400 AD; the Tigara sample derives from Point Hope, Alaska between 1200-1700 AD.

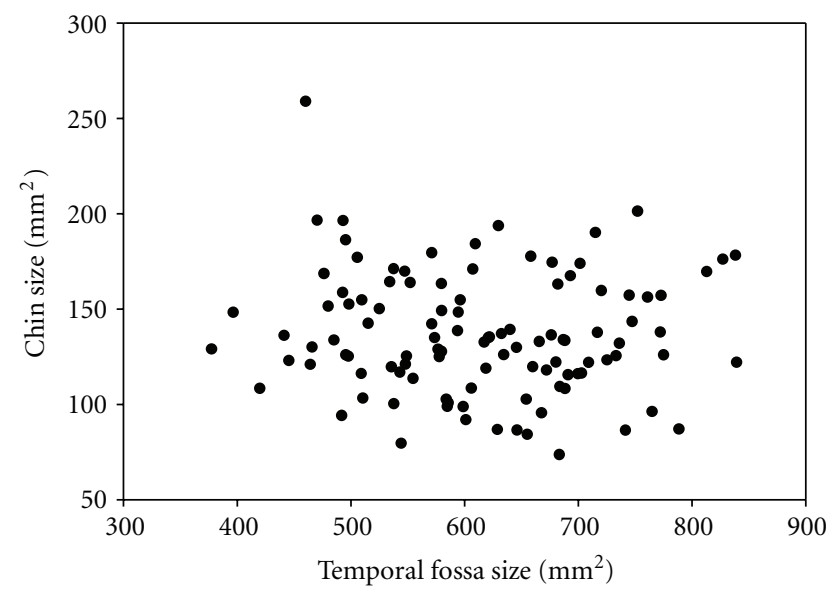

FIGURE 7: Chin size relative to temporal fossa size for a mixed-sex sample of adult modern humans from the Tigara $(N=57)$ and El Hesa $(N=51)$ collections housed at the American Museum of Natural History. Chin size is determined as a simple product of midsagittal height and chin thickness at the tuber symphyseos, and temporal fossa size is likewise the product of fossa length and breadth. If temporal fossa size is proportional to temporalis crosssectional area, this variable serves as a proxy for adductor force, meaning that positive correlation of chin size and fossa size is expected if masticatory mechanics are functionally linked to corpus morphology. Regression is nonsignificant $(P=0.50)$, suggesting a lack of functional relationship.

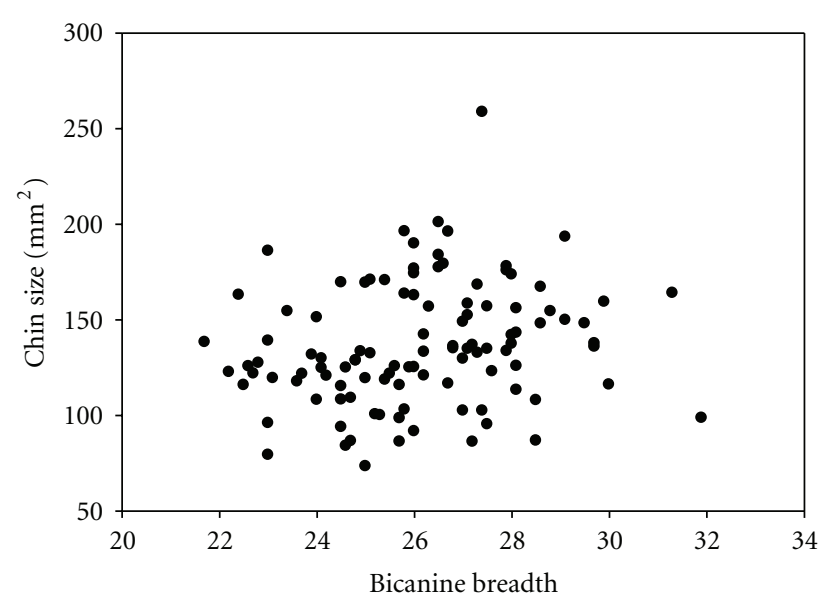

Figure 8: Chin size $\left(\mathrm{mm}^{2}\right)$ relative to bicanine breadth $(\mathrm{mm})$ for a mixed-sex sample of adult modern humans from the Tigara $(N=$ $57)$ and El Hesa $(N=51)$ collections. Daegling [14] hypothesized that bicanine breadth would covary positively with chin size as this represented the portion of the anterior corpus loaded in coronal bending due to twisting of the postcanine corpora. Regression is significant at $P=0.04$; however, $r^{2}=0.04$, indicating that little of the variation in chin size is explicable by variation in bicanine breadth.

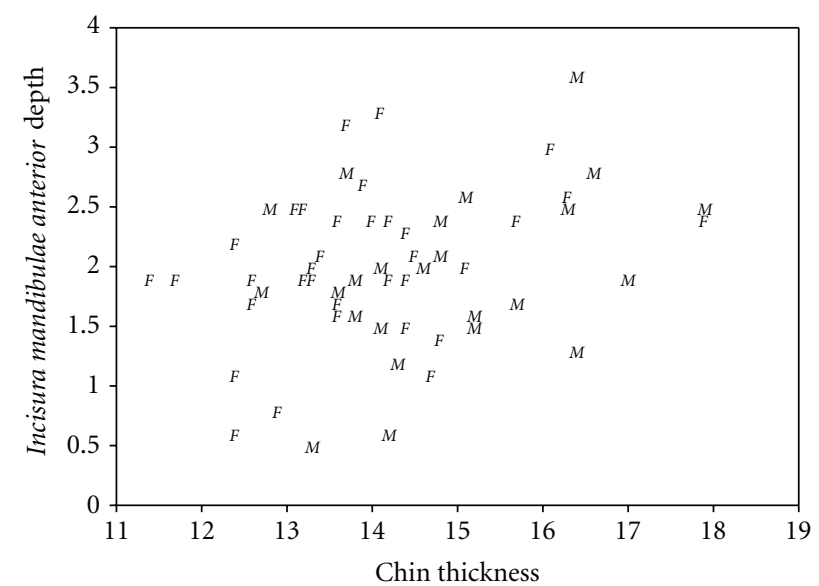

FIGURE 9: The depth of the anterior incurvatio of the human chin (units in $\mathrm{mm}$ ) is contrasted with the thickness of the chin ( $\mathrm{mm}$ ) at the tuber symphyseos in the Tigara sample. Thickness is measured perpendicular to the vertical tangent at the most anterior point of the symphyseal tuber; this measurement will be approximately parallel to the occlusal plane. Sexing for the sample is based on Costa [79] who employed multiple criteria including features of the os coxae. A deep incisura generally gives the appearance of a more salient chin, while chin thickness provides a size measure with no necessary indication of distinctiveness. Interestingly, the different shapes said to differentiate males from females are not reflected by these measures, that is, there is substantial overlap of the sexes. Thus, there is no definitive sex difference in shape (as measured here) of the chin in midsagittal section. Nevertheless, regression is significant $(P=0.02)$, indicating that large chins are also more salient, in that they are associated with larger anterior incisures. Comparison of sexes by analysis of covariance (ANCOVA) reveals no significant difference between male and female slopes $(P=0.90)$ or intercepts $(P=0.14)$. 


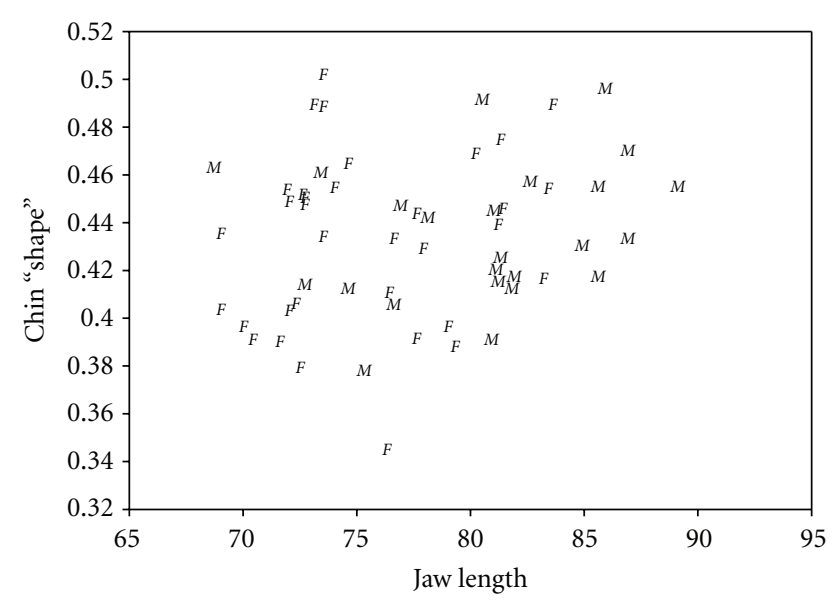

Figure 10: An index of chin breadth/height ("shape") is contrasted with a measure of jaw size (mandibular length, units in $\mathrm{mm}$ ) for the Tigara sample. Sexing for the sample is based on Costa [79]. Regression is nonsignificant $(P=0.15)$, indicating that the general geometry of the human symphysis is insensitive to size. The female sample range encompasses the male range for shape. Thus, shape differences are not apparent between the sexes in midsagittal section. Comparison of sexes by analysis of covariance (ANCOVA) reveals no significant difference between male and female slopes $(P=0.89)$ or intercepts $(P=0.68)$.

feature that cannot be assessed in exactly the same terms; that is, every morphological feature can be accurately described as developmentally determined. The finding of cortical hypertrophy does refocus the issue somewhat: why would a mere artifact be associated with such a heavy metabolic investment (assuming the form of the chin and the bone beneath it have something to do with one another)?

With certain specific considerations, the idea of the form of the chin having nothing much to do with mechanical function is more plausible. Weidenreich [13] offered a compelling, but very simple, explanation for the chin's salience. He noted that modern human incisors are highly reduced relative to earlier hominins or for that matter, hominoids. The human chin is thus the consequence of reduced alveolar support for diminutive teeth. The appearance of the chin, therefore, will coincide with incisor root reduction in human evolution. This explanation by itself fails to explain why the basal portion of the symphysis protrudes anteriorly; that is, its persistence conceivably betrays some functional imperative. Krantz [81] opined that space was at a premium in the modern human oral cavity, essentially arguing that the basal portion of the mandible could not retract and still leave sufficient room for the oral viscera. Weidenreich's position is particularly germane to the question of the form of the chin and inferences about function, because it underscores the possibility that the chin itself is the result of separate functional requirements.

Similarly, there is the possibility that cortical hypertrophy in recent humans is an allometric artifact that requires no biomechanical or adaptive explanation. It simply may be that bone volume in human mandibles is phylogenetically conserved, while the overall size of the corpus has undergone

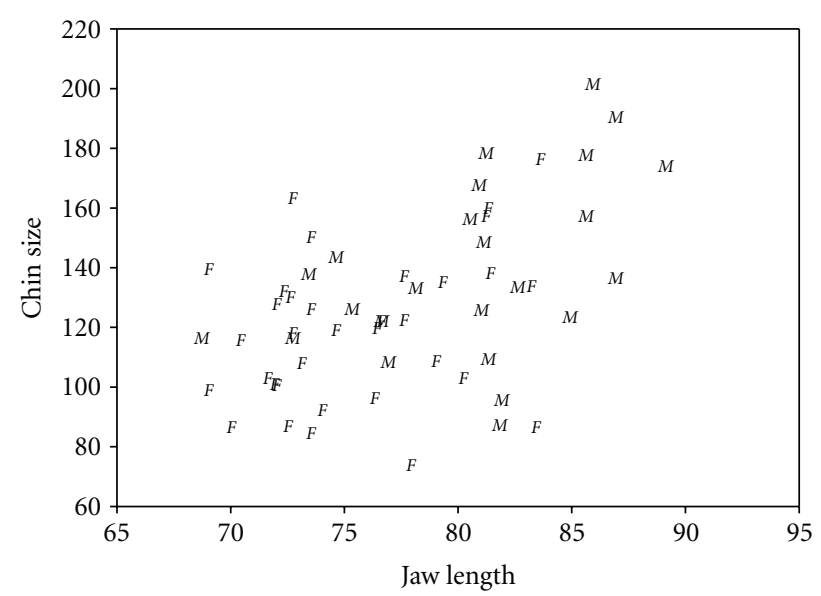

Figure 11: Chin size (determined as the product of height and breadth $)$ is positively associated with jaw length $\left(P<0.001 ; r^{2}=\right.$ 0.24 ), with substantial overlap of the sexes in both variables. This significant finding is suggestive of a functional relationship, but the correlation is plausibly reflected as a general effect of body size dimorphism. Daegling's [14] model of the masticatory loading of the chin emphasized coronal bending of the anterior corpus due to twisting of the postcanine corpora. Torsion of the corpora, however, has no necessary scaling relationship with mandibular length. Alternatively, this relationship could reflect a structural response to wishboning strains [68], although it is not known whether this load occurs in human mastication. Comparison of sexes by analysis of covariance (ANCOVA) reveals no significant difference between male and female slopes $(P=0.47)$ or intercepts $(P=0.21)$.

reduction. To some degree, the apparently exceptional enamel thickness in modern humans can be explained in this way $[82,83]$. If this is the correct interpretation, however, a mechanobiological role for modulation of bone mass is denied or at least requires an exception in the modern human case. This amounts to special pleading in the absence of specific tests.

3.4. The Chin and Language. The latest contribution to the role of language in determining the form of the chin is the finite-element study of Ichim et al. [7]. Noting that their previous iterations [75] showed no advantage to the chin for masticatory stress, they argued that in a hypothetical nonchinned mandible, the action of Genioglossus muscle at a particular orientation produced elevated stresses along the labial anterior corpus reminiscent of the trigonum mentale that typifies many human chins. From this, they suggested that the appearance of language precipitated the formation of the chin.

As noted above, the small strain magnitudes that are produced in speech may not disqualify the idea that this activity could influence the distribution of bone tissue. Instead, the real issue with this study is whether the isolated action of Genioglossus (and its inferred line of action) provides a realistic load case for spoken language. As several other muscles are involved, this would seem to be unlikely. More importantly, it is also doubtful that Genioglossus is the 
sole culprit for the chin in light of other data concerning the muscle's function. Acting to protrude the tongue, the genioglossus is critical for prevention of tongue relapse which could obstruct the airway of the oropharynx. Consequently, the muscle is active during respiration and particularly during inspiration in alert humans [84]. During sleep, the muscle shows more or less continuous activity, elevated during inspiration, with the exception of intermittent quiescent activity during REM sleep $[85,86]$. Consequently, activity in the Genioglossus is producing low-level strains in the mandible whether or not speaking is taking place. Despite the uniqueness of their laryngeal space, humans do not appear to be idiosyncratic in recruiting Genioglossus for maintaining respiratory airflow $[87,88]$. Frequent and ubiquitous activity in Genioglossus is thus not particular to humans, even if the activity of this muscle during speech is; therefore, the mechanobiological stimulus of this muscle with respect to mandibular bone is probably not sufficiently unique in people to suppose that it alone counts for symphyseal morphology.

There are additional interpretive problems with Ichim et al.'s [7] model. By ignoring the suprahyoid muscles as well as those from the trigeminal and facial somitomeres, the loadcase that induces the stress field that they accord significant is highly unrealistic and unsupported by independent data. Recruitment of these other muscles which are known to function during speech $[55,56,89]$ necessarily changes the details of the stress field in the anterior corpus. Determining the accuracy of a modeled stress field is a formidable task, but even with such a depiction, relating the details of stress magnitudes and gradients to the specific details of chin morphology is even more challenging. Furthermore, anecdotal observation suggests that the mere appearance of the chin has no necessary connection to language use, regardless of underlying bony morphology. Angelman's syndrome is a developmental disorder in which severe limitation or absence of spoken language is one symptom, yet individuals presenting with this syndrome are described as having prominent chins [90].

Finally, it should be recognized that the semantics of the "chin problem" do matter for its resolution [16]. If one defines the chin by criteria of the tuber symphyseos, tubercula lateralia, and the incurvatio mandibularis, identifying a biomechanical milieu which accounts for this constellation of features is exceedingly difficult. On the other hand, if one accepts the heuristic definition that it is "but a blob of bone" [11, page 4] then deciding its evolutionary significance is a tidier endeavor, if not more imprecise. Focusing exclusively on the property of bone mass, the mystery of the chin still prevails; it is likely that there is more bone here than we need. Our confusion stems from the underlying assumption that the goal of bone formation and maintenance is to make sure that bones are exactly as strong as they need to be. Natural selection need not lead to this state of affairs [91].

What is important to disentangle is whether cortical hypertrophy itself explains the human chin. If bone hypertrophy is localized at the labial swelling of the human symphysis (tuber symphyseos), then the chin and cortical hypertrophy could be reasonably viewed as part of a single structural (and perhaps functional) complex, depending on one's definition of the chin. Fukase's [70] work, however, indicates that cortical packing characterizes the basal symphysis as a whole, and the lingual basal region (i.e., in the vicinity of the genial spines) is where cortical bone is thickest. Thick cortical bone is not a requirement for the mentum osseum.

\section{Testing the Speech Hypothesis}

One apparent problem with the speech hypothesis is that the load frequencies inferred above for speech are still very low compared to the experimental conditions under which bone tissue responds to low-strain magnitudes $(30 \mathrm{~Hz})$. If speech produces load frequencies of over $5 \mathrm{~Hz}$, this is close to the lower bound of bone sensitivity to low-magnitude strains [42] but well below the ideal frequencies for inducing bone augmentation [92]. There are, however, two considerations that suggest that the physiology of speech could effectively induce bone formation. First, it may be the result of actions associated with the muscles involved in speech but not necessarily those confined to the active production of speech. Muscle activity occurring during relatively nonvigorous but ubiquitous events (e.g., in maintaining mandibular "posture") is implicated in producing high-frequency $(10-50 \mathrm{~Hz})$ but low-amplitude strains that appear to be important in stimulating bone formation [52, 93]. Since the structural characteristics of human muscles involved in speech differ from their homologues in nonhuman primates [94], then the effects of these muscles in postural maintenance may be qualitatively distinct. A second consideration is that the bone literature is replete with examples of dynamic loads of varying magnitudes and frequencies having measurable effects on bone modeling and remodeling. Clearly, the skeleton can respond to a range of combinations of load frequency and magnitude [45]. If bone is sensitive to the interplay of daily loading cycles and average cyclical peak strains, speech may provide a potent stimulus for bone formation that is unusual among primates. It has been emphasized that the ability of low strains to engender metabolic response in bone is intimately tied to the number of loading cycles per day [52, 92]. Given the discussion of frequencies above, the number of loading cycles per day owing to speech may be orders of magnitude higher than those associated with mastication. While the appropriate data are lacking, a thought experiment may underscore the plausibility of the speech hypothesis. Assuming a load frequency of $5 \mathrm{~Hz}$, speaking for 5-10 minutes an hour for 16 hours produces $24,000-48,000$ loading cycles in a single day. This range encompasses the 36,000 cycle daily stimulus that can promote bone activity with strains as small as 5$10 \mu \varepsilon[52,95]$. Unresisted opening of the jaws in macaques creates bending strains of $\sim 100 \mu \varepsilon$, and licking behaviors create strains between $100-300 \mu \varepsilon$ [68]. Even granting the excessive amount of bone in human jaws, it appears likely that strains engendered during speech would exceed $5 \mu \varepsilon$.

A desired initial test of the speech hypothesis is the examination of the assumptions recruited in the above argument. That is, how do speech rates and frequencies compare with 
those of mastication over day-to-day intervals? Modeling the actions and activity of all the muscles involved with speech is obviously an involved undertaking, but without such information the nature of loads and the concomitant stresses in the human mandible, the biomechanical effects of speech will remain uncertain. In general terms, the details of bone deployment in the human mandibular corpus would suggest that speech produces stress patterns which induce modeling and remodeling that are for the most part localized in the anterior corpus. Theoretical or experimental evidence to the contrary would undermine the hypothesized relationship.

A second test is developmental: assuming the pattern of cortical bone distribution is not established in utero or prior to language acquisition, the adoption of speech may be associated with ontogenetic changes in bone mass in the corpus. The weakness of this test, however, is in these initial assumptions that the general pattern of bone distribution is developmentally labile in the extreme. There exist data to suggest that this is a naive premise and that skeletal mass and geometry are subject to species-specific canalization [96], despite the capacity for bone to change mass and geometry developmentally. Bone packing in the human symphysis, despite being quantitatively distinct from other primates, is still highly variable in that the fraction of symphyseal crosssectional area occupied by cortical bone can range from 32$72 \%$ [17]. Given the difficulties facing us in interpreting the relationship of skeletal form to physiological activity [97], we should be loath to assume that most of this variance in relative bone thickness is explained primarily by whether an individual was verbose or taciturn. Given experimental designs that have uncovered the influence of high-frequency strains to bone metabolism, one hypothesis worth exploring is that the onset of speech activity is associated with increases in mandibular bone mass. Certainly suckling activity immediately provides a high-frequency, low-magnitude environment in all mammals postnatally, but the developmental timing in human speech acquisition is sufficiently narrow that our discrimination of a temporally specific period of bone hypertrophy should be possible.

The implications of this hypothesis-that articulate speech underlies cortical hypertrophy in human mandibles-for paleoanthropological inference are large, but the current absence of supportive data means that its application to the fossil record is largely speculative. There is, however, one scenario which itself could provide an important, if not decisive, test. Given that language is a symbolic capacity and that some aspects of material culture have unmistakable symbolic content, it is reasonable to assume that the presence of symbolic, nonutilitarian artifacts is indicative of the capacity for language. The presence of a nonhuman pattern of bone distribution in hominin mandibles which are associated with symbolic artifacts would essentially refute the speech hypothesis. Alternatively, provided supportive experimental and developmental data are collected, the observation of cortical hypertrophy in the human fossil record could productively inform questions of the appearance of modern human behaviors [98] through inference of language ability.

Despite the abundance of mandibular remains in the hominin fossil record, information on cortical bone distri- bution in the anterior corpus is relatively meager. Specimens which preserve the symphyseal region (e.g., the SKW 5 mandible of Paranthropus robustus) may nevertheless not preserve the internal contours of bone very well due to factors of fossilization [99]. The anterior corpus of SK 15 (the type of "Telanthropus," likely an early species of Homo) is unlike that of modern humans in terms of geometry (i.e., it lacks a discernible chin) but occupies the lower end of the modern human range in terms of cortical area, relative to both subperiosteal area and mandibular length [23]. Homo floresiensis mandibles are quite unlike modern humans in terms of symphyseal morphology and relative corpus size; published CT images do not indicate the modern human pattern of cortical hypertrophy, at least in the postcanine corpus [100]. Neanderthal mandibular remains have been examined by computed tomography $[101,102]$, so at least some data needed to investigate cortical packing in $H$. neanderthalensis are already collected. A finding of cortical hypertrophy in mandibles lacking a chin among Pleistocene Homo in association with indications of symbolic behavior (e.g., [103]) would suggest that the modern human chin is not a diagnostic feature of articulate speech.

\section{Rethinking Functional Adaptation}

The distilled version of Wolff's Law, that maximation of strength with a minimum of material is the selective target of bone metabolic activity, has been rightly criticized in recent years owing to an accumulation of contrary data $[44,97,104-106]$. The idea that bone morphology represents a structural solution to minimize biomechanical stress is no longer tenable, but what exactly is being optimized in the skeleton is enigmatic [93]. Whether the proposed linkage of speech to mandibular bone distribution is valid or not, what seems clear is that bone deployment in the mandible is suboptimal with respect to a criterion of obtaining a globally constant relationship between stress and strength. Perhaps what we are observing is instead a general strategy of bone adaptation in which the particulars of a loadcase are less important that the general dynamic features of a loading regime, such that the metabolic activity of bone is effective but not necessarily economical with respect to structural integrity.

\section{Conclusions}

High-frequency, low-magnitude loads associated with articulate speech are hypothesized to explain the apparent paradox of hypertrophied mandibular bone in contrast to the reduced bone thickness that typifies the remainder of the modern human skull. Current understanding of bone metabolic activity is consistent with the hypothesis that speech production accounts for the relatively greater bone volume that typifies human mandibles in contrast to nonhuman primates. The detection of elevated bone mass in fossil mandibles may thus provide insight into the origins of speech in human evolution.

The fact that the greatest concentration of cortical bone within sections is most apparent in the anterior mandible is consistent with inference of the general effects of jaw 
loading during speech. Bending moments from the muscles of mastication will be largest in midsagittal section and Geniohyoid, Genioglossus and Anterior Digastric muscles, which are intimately involved in speech production, directly attach in this region as well.

This hypothesis is testable by different means, but at present it is not directly supported by experimental, developmental or comparative data. Instead, the observations on bone mass in human mandibles are merely consistent with the idea that the mechanobiology of speech can effect bone formation to a significant degree. In addition, whether bone hypertrophy is functionally linked to the evolutionary appearance of the chin remains an open, and to some degree separate, question.

\section{Acknowledgments}

Data collected for this project was supported in part by NSF (BNS 8920592 and BCS 0922429) and by an American Museum of Natural History Collection Study grant to the author in 1992. The author also wishes to thank Ian Tattersall and Gary Sawyer for their support and assistance during my stay at the museum. K. Kupczik and an anonymous reviewer provided helpful critique and commentary on a previous draft.

\section{References}

[1] W. L. Jungers, A. A. Pokempner, R. F. Kay, and M. Cartmill, "Hypoglossal Canal Size in Living Hominoids and the Evolution of Human Speech," Human Biology, vol. 75, no. 4, pp. 473-484, 2003.

[2] B. Arensburg, L. A. Schepartz, A. M. Tillier, B. Vandermeersch, and Y. Rak, "A reappraisal of the anatomical basis for speech in middle Palaeolithic hominids," American Journal of Physical Anthropology, vol. 83, no. 2, pp. 137-146, 1990.

[3] D. Degusta, W. H. Gilbert, and S. P. Turner, "Hypoglossal canal size and hominid speech," Proceedings of the National Academy of Sciences of the United States of America, vol. 96, no. 4, pp. 1800-1804, 1999.

[4] R. F. Kay, M. Cartmill, and M. Balow, "The hypoglossal canal and the origin of human vocal behavior," Proceedings of the National Academy of Sciences of the United States of America, vol. 95, no. 9, pp. 5417-5419, 1998.

[5] J. T. Laitman and R. C. Heimbuch, "The basicranium of PlioPleistocene hominids as an indicator of their upper respiratory systems," American Journal of Physical Anthropology, vol. 59, no. 3, pp. 323-343, 1982.

[6] P. Lieberman, J. T. Laitman, J. S. Reidenberg, K. Landahl, and P. J. Gannon, "Folk psychology and talking hyoids," Nature, vol. 342, no. 6249, pp. 486-487, 1989.

[7] I. Ichim, J. Kieser, and M. Swain, "Tongue contractions during speech may have led to the development of the bony geometry of the chin following the evolution of human language: a mechanobiological hypothesis for the development of the human chin," Medical Hypotheses, vol. 69, no. 1, pp. 20-24, 2007.

[8] A. Keith, Antiquity of Man, Williams and Norgate, London, $\mathrm{UK}, 1916$.

[9] O. Walkhoff, "Die menschliche Sprache in ihrer Bedeutung fur die funktionelle Gestalt des Unterkiefers," Anatomischer Anzeiger, vol. 24, p. 129, 1904.
[10] R.H. Biggerstaff, "The biology of the human chin," in Orofacial Growth and Development, A. A Dahlberg and T. M. Graber, Eds., pp. 71-87, Mouton, Paris, France, 1977.

[11] E.L. DuBrul and H. Sicher, The Adaptive Chin, Charles C. Thomas, Springfield, Ill, USA, 1954.

[12] T. T. Waterman, "The evolution of the chin," American Naturalist, vol. 50, pp. 237-242, 1916.

[13] F. Weidenreich, "The mandibles of Sinanthropus pekinensis: a comparative study," Palaeontologica Sinica Series D, vol. 7, pp. 1-164, 1936.

[14] D. J. Daegling, "Functional morphology of the human chin," Evolutionary Anthropology Issues, News, and Reviews, vol. 1, no. 5, pp. 170-177, 1993.

[15] S. D. Dobson and E. Trinkaus, "Cross-sectional geometry and morphology of the mandibular symphysis in Middle and Late Pleistocene Homo," Journal of Human Evolution, vol. 43, no. 1, pp. 67-87, 2002.

[16] J. H. Schwartz and I. Tattersall, "The human chin revisited: what is it and who has it?" Journal of Human Evolution, vol. 38 , no. 3, pp. 367-409, 2000.

[17] D. J. Daegling, "Relationship of bone utilization and biomechanical competence in hominoid mandibles," Archives of Oral Biology, vol. 52, no. 1, pp. 51-63, 2007.

[18] W. L. Hylander, "Mandibular function and biomechanical stress and scaling," Integrative and Comparative Biology, vol. 25, no. 2, pp. 315-330, 1985.

[19] M. J. Ravosa, "Jaw morphology and function in living and fossil Old World monkeys," International Journal of Primatology, vol. 17, no. 6, pp. 909-932, 1996.

[20] M. J. Ravosa, "Size and scaling in the mandible of living and extinct apes," Folia Primatologica, vol. 71, no. 5, pp. 305-322, 2000.

[21] M. Bouvier, "Biomechanical scaling of mandibular dimensions in New World Monkeys," International Journal of Primatology, vol. 7, no. 6, pp. 551-567, 1986.

[22] M. J. Ravosa, "Structural allometry of the prosimian mandibular corpus and symphysis," Journal of Human Evolution, vol. 20, no. 1, pp. 3-20, 1991.

[23] D.J. Daegling, Geometry and biomechanics of hominoid mandibles, Ph.D. dissertation, State University of New York, Stony Brook, NY, USA, 1990.

[24] M. A. McCollum, C. C. Sherwood, C. J. Vinyard, C. O. Lovejoy, and F. Schachat, "Of muscle-bound crania and human brain evolution: the story behind the MYH16 headlines," Journal of Human Evolution, vol. 50, no. 2, pp. 232-236, 2006.

[25] H. H. Stedman, B. W. Kozyak, A. Nelson et al., "Myosin gene mutation correlates with anatomical changes in the human lineage," Nature, vol. 428, no. 6981, pp. 415-418, 2004.

[26] R. Wrangham and N. Conklin-Brittain, "Cooking as a biological trait," Comparative Biochemistry and Physiology A, vol. 136, no. 1, pp. 35-46, 2003.

[27] K. R. Agrawal, P. W. Lucas, J. F. Prinz, and I. C. Bruce, "Mechanical properties of foods responsible for resisting food breakdown in the human mouth," Archives of Oral Biology, vol. 42, no. 1, pp. 1-9, 1997.

[28] L. M. Waugh, "Influence of diet on the jaw and face of the American Eskimo," Journal of the American Dental Association, vol. 24, pp. 1640-1647, 1937.

[29] E. Helkimo, G. E. Carlsson, and M. Helkimo, "Bite force and state of dentition," Acta Odontologica Scandinavica, vol. 35, no. 6, pp. 297-303, 1977.

[30] G. J. Pruim, H. J. de Jongh, and J. J. Ten Bosch, "Forces acting on the mandible during bilateral static bite at different bite 
force levels," Journal of Biomechanics, vol. 13, no. 9, pp. 755$763,1980$.

[31] D. P. Sinn, E. A. de Assis, and G. S. Throckmorton, "Mandibular excursions and maximum bite forces in patients with temporomandibular joint disorders," Journal of Oral and Maxillofacial Surgery, vol. 54, no. 6, pp. 671-679, 1996.

[32] M. C. Raadsheer, T. M. G. J. van Eijden, F. C. van Ginkel, and B. Prahl-Andersen, "Contribution of jaw muscle size and craniofacial morphology to human bite force magnitude," Journal of Dental Research, vol. 78, no. 1, pp. 31-42, 1999.

[33] B. Demes and N. Creel, "Bite force, diet, and cranial morphology of fossil hominids," Journal of Human Evolution, vol. 17, no. 7, pp. 657-670, 1988.

[34] S. Wroe, T. L. Ferrara, C. R. McHenry, D. Curnoe, and U. Chamoli, "The craniomandibular mechanics of being human," Proceedings of the Royal Society B, vol. 277, no. 1700, pp. 3579-3586, 2010.

[35] P. W. Lucas, C. R. Peters, and S. R. Arrandale, "Seed-breaking forces exerted by orang-utans with their teeth in captivity and a new technique for estimating forces produced in the wild," American Journal of Physical Anthropology, vol. 94, no. 3, pp. 365-378, 1994.

[36] D. R. Carter and G. S. Beaupre, Skeletal Function and Form, Cambridge University Press, Cambridge, UK, 2001.

[37] L. E. Lanyon and C. T. Rubin, "Functional adaptation in skeletal structures," in Functional Vertebrate Morphology, M. Hildebrand, D. M. Bramble, K. F. Liem, and D. B. Wake, Eds., pp. 1-25, Harvard University Press, Cambridge, Mass, USA, 1985.

[38] R. B. Martin, D. B. Burr, and N. A. Sharkey, Skeletal Tissue Mechanics, Springer, New York, NY, USA, 1998.

[39] L. E. Lanyon and C. T. Rubin, "Static vs dynamic loads as an influence on bone remodelling," Journal of Biomechanics, vol. 17, no. 12, pp. 897-905, 1984.

[40] H. M. Frost, "Bone "mass" and the "mechanostat": a proposal," Anatomical Record, vol. 219, no. 1, pp. 1-9, 1987.

[41] C. T. Rubin and L. E. Lanyon, "Regulation of bone mass by mechanical strain magnitude," Calcified Tissue International, vol. 37, no. 4, pp. 411-417, 1985.

[42] C. T. Rubin, K. J. McLeod, T. S. Gross, and H. J. Donahue, "Physical stimulus as potent determinants of bone morphology," in Bone Biodynamics in Orthodontic and Orthopedic Treatment, D. S. Carlson and S. A. Goldstein, Eds., pp. 7591, University of Michigan Center for Human Growth and Development, Ann Arbor, Mich, USA, 1991.

[43] Y. F. Hsieh and C. H. Turner, "Effects of loading frequency on mechanically induced bone formation," Journal of Bone and Mineral Research, vol. 16, no. 5, pp. 918-924, 2001.

[44] D. J. Daegling, "The relationship of in vivo bone strain to mandibular corpus morphology in Macaca fascicularis," Journal of Human Evolution, vol. 25, no. 4, pp. 247-269, 1993.

[45] D. M. Cullen, R. T. Smith, and M. P. Akhter, "Bone-loading response varies with strain magnitude and cycle number," Journal of Applied Physiology, vol. 91, no. 5, pp. 1971-1976, 2001.

[46] M. R. Forwood and C. H. Turner, "The response of rat tibiae to incremental bouts of mechanical loading: a quantum concept for bone formation," Bone, vol. 15, no. 6, pp. 603609, 1994.

[47] J. E. A. Wolff, "A theoretical approach to solve the chin problem," in Food Acquisition and Processing in Primates, D. J. Chivers, B. A. Wood, and A. Bilsborough, Eds., pp. 391-405, Plenum Press, New York, NY, USA, 1984.
[48] D. E. Lieberman, "How and why humans grow thin skulls: experimental evidence for systemic cortical robusticity," American Journal of Physical Anthropology, vol. 101, no. 2, pp. 217-236, 1996.

[49] C. S. Larsen, Bioarchaeology: Interpreting Behavior from the Human Skeleton, Cambridge University Press, Cambridge, UK, 1997.

[50] D. C. M. Boyd, A Functional Model for Masticatory-Related Mandibular, Dental, and Craniofacial Microevolutionary Change Derived from a Selected Southeastern Indian Skeletal Temporal Series, University of Tennessee, Knoxville, Tenn, USA, 1988.

[51] C. S. Larsen, “The anthropology of St. Catherine's Islandpp. 3. prehistoric human biological adaptation," Anthropological Papers of the American Museum of Natural History, vol. 57, no. 3, pp. 155-276, 1982.

[52] C. Rubin, A. S. Turner, C. Mallinckrodt, C. Jerome, K. Mcleod, and S. Bain, "Mechanical strain, induced noninvasively in the high-frequency domain, is anabolic to cancellous bone, but not cortical bone," Bone, vol. 30, no. 3, pp. 445-452, 2002.

[53] C. Rubin, A. S. Turner, S. Bain, C. Mallinckrodt, and K. McLeod, "Low mechanical signals strengthen long bones," Nature, vol. 412, no. 6847, pp. 603-604, 2001.

[54] V. Gilsanz, T. A. L. Wren, M. Sanchez, F. Dorey, S. Judex, and C. Rubin, "Low-level, high-frequency mechanical signals enhance musculoskeletal development of young women with low BMD," Journal of Bone and Mineral Research, vol. 21, no. 9, pp. 1464-1474, 2006.

[55] J. W. Folkins, "Muscle activity for jaw closing during speech," Journal of Speech and Hearing Research, vol. 24, no. 4, pp. 601-615, 1981.

[56] K. M. Hiiemae and J. B. Palmer, "Tongue movements in feeding and speech," Critical Reviews in Oral Biology and Medicine, vol. 14, no. 6, pp. 413-429, 2003.

[57] M. Kumada, R. T. Todd, F. Bell-Berti, M. Niitsu, H. Hirose, and S. Niimi, "Functions of the muscles of the tongue during speech," Journal of the Acoustical Society of America, vol. 104, no. 3, pp. 1819-1820, 1998.

[58] C. F. Ross, D. A. Reed, R. L. Washington, A. Eckhardt, F. Anapol, and N. Shahnoor, "Scaling of chew cycle duration in primates," American Journal of Physical Anthropology, vol. 138, no. 1, pp. 30-44, 2009.

[59] C. Lassauzay, M. A. Peyron, E. Albuisson, E. Dransfield, and A. Woda, "Variability of the masticatory process during chewing of elastic model foods," European Journal of Oral Sciences, vol. 108, no. 6, pp. 484-492, 2000.

[60] D. J. Ostry and J. R. Flanagan, "Human jaw movement in mastication and speech," Archives of Oral Biology, vol. 34, no. 9, pp. 685-693, 1989.

[61] E. Fosler-Lussier and N. Morgan, "Effects of speaking rate and word frequency on pronunciations in conversational speech," Speech Communication, vol. 29, no. 2, pp. 137-158, 1999.

[62] H. Kuwabara, "Acoustic and perceptual properties of phonemes in continuous speech as a function of speaking rate," in Proceedings of the 5th European Conference on Speech Communication and Technology (EUROSPEECH '97 ), pp. 1003-1006, Rhodes, Greece, 1997.

[63] M. A. Levent and H. L. H. John, "A study of temporal features and frequency characteristics in American English foreign accent," Journal of the Acoustical Society of America, vol. 102, no. 1, pp. 28-40, 1997. 
[64] N. Morgan and E. Fosler-Lussier, "Combining multiple estimators of speaking rate," Acoustics, Speech and Signal Processing, vol. 2, pp. 729-732, 1998.

[65] T. W. P. Korioth, D. P. Romilly, and A. G. Hannam, “Threedimensional finite element stress analysis of the dentate human mandible," American Journal of Physical Anthropology, vol. 88, no. 1, pp. 69-96, 1992.

[66] M. Motoyoshi, Y. Hama, E. Sugi, K. Takahashi, K. Kamijo, and S. Namura, "A finite element model of the human face. Stress distribution around the chin due to articulation of the five vowels in Japanese," The Journal of Nihon University School of Dentistry, vol. 38, no. 1, pp. 11-20, 1996.

[67] J. T. Stern Jr., Essentials of Gross Anatomy, FA Davis, Philadelphia, Pa, USA, 1988.

[68] W. L. Hylander, "Stress and strain in the mandibular symphysis of primates: a test of competing hypotheses," American Journal of Physical Anthropology, vol. 64, no. 1, pp. $1-46,1984$.

[69] B. Tuller, K. S. Harris, and B. Gross, "Electromyographic study of the jaw muscles during speech," Journal of Phonetics, vol. 9, pp. 175-188, 1981.

[70] H. Fukase, "Functional significance of bone distribution in the human mandibular symphysis," Anthropological Science, vol. 115, no. 1, pp. 55-62, 2007.

[71] N. Barber, "The evolutionary psychology of physical attractiveness: sexual selection and human morphology," Ethology and Sociobiology, vol. 16, no. 5, pp. 395-424, 1995.

[72] K. Grammer and R. Thornhill, "Human (Homo sapiens) facial attractiveness and sexual selection: the role of symmetry and averageness," Journal of Comparative Psychology, vol. 108, no. 3, pp. 233-242, 1994.

[73] D. E. Lieberman, "Testing hypotheses about recent human evolution from skulls: integrating morphology, function, development, and phylogeny," Current Anthropology, vol. 36, no. 2, pp. 159-197, 1995.

[74] F. Gröning, J. Liu, M. J. Fagan, and P. O’Higgins, "Why do humans have chins? Testing the mechanical signficance of modern human symphyseal morphology with finite element analysis," American Journal of Physical Anthropology, vol. 144, pp. 593-606, 2011.

[75] I. Ichim, M. Swain, and J. A. Kieser, "Mandibular biomechanics and development of the human chin," Journal of Dental Research, vol. 85, no. 7, pp. 638-642, 2006.

[76] R. J. Smith, "Categories of allometry: body size versus biomechanics," Journal of Human Evolution, vol. 24, no. 3, pp. 173-182, 1993.

[77] W. M. Bass, Human Osteology: A Laboratory and Field Manual, Missouri Archaeological Society, Columbia, Mo, USA, 3rd edition, 1987.

[78] M. Coquerelle, F. L. Bookstein, and J. Braga et al., "Sexual dimorphism of the human mandible and its association with dental development," American Journal of Physical Anthropology, vol. 145, no. 2, pp. 192-202, 2011.

[79] R. L. Costa, Dental pathology and related factors in archaeological eskimo samples from point hope and Kodiak Island, Alaska, Ph.D. dissertation, University of Pennsylvania, 1977.

[80] S. J. Gould and R. C. Lewontin, "The spandrels of San Marco and the Panglossian paradigm: a critique of the adaptationist programme," Proceedings of the Royal Society of London B, vol. 205, no. 1161, pp. 581-598, 1979.

[81] G. S. Krantz, "Sapienization and speech," Current Anthropology, vol. 21, no. 6, pp. 773-792, 1980.

[82] A. J. Olejniczak, T. M. Smith, R. N. M. Feeney et al., "Dental tissue proportions and enamel thickness in Neandertal and modern human molars," Journal of Human Evolution, vol. 55, no. 1, pp. 12-23, 2008.

[83] K. Kupczik and J. J. Hublin, "Mandibular molar root morphology in Neanderthals and Late Pleistocene and recent Homo sapiens," Journal of Human Evolution, vol. 59, no. 5, pp. 525-541, 2010.

[84] E. K. Sauerland and S. P. Mitchell, "Electromyographic activity of the human Genioglossus muscle in response to respiration and to positional changes of the head," Bulletin of the Los Angeles neurological societies, vol. 35, no. 2, pp. 69-73, 1970.

[85] R. C. Basner, J. Ringler, R. M. Schwartzstein, S. E. Weinberger, and J. Woodrow Weiss, "Phasic electromyographic activity of the genioglossus increases in normals during slow-wave sleep," Respiration Physiology, vol. 83, no. 2, pp. 189-200, 1991.

[86] E. K. Sauerland and R. M. Harper, "The human tongue during sleep: electromyographic activity of the genioglossus muscle," Experimental Neurology, vol. 51, no. 1, pp. 160-170, 1976.

[87] R. T. Brouillette and B. T. Thach, "Control of genioglossus muscle inspiratory activity," Journal of Applied Physiology Respiratory Environmental and Exercise Physiology, vol. 49, no. 5, pp. 801-808, 1980.

[88] R. F. Fregosi and D. D. Fuller, "Respiratory-related control of extrinsic tongue muscle activity," Respiration Physiology, vol. 110, no. 2-3, pp. 295-306, 1997.

[89] S. M. Farret, M. Vitti, and M. M. B. Farret, "Electromyographic analysis of the mentalis and depressor labii inferior muscles in the production of speech," Electromyography and Clinical Neurophysiology, vol. 22, no. 1-2, pp. 137-148, 1982.

[90] J. Clayton-Smith and L. Laan, "Angelman syndrome: a review of the clinical and genetic aspects," Journal of Medical Genetics, vol. 40, no. 2, pp. 87-95, 2003.

[91] N. C. Nowlan and P. J. Prendergast, "Evolution of mechanoregulation of bone growth will lead to non-optimal bone phenotypes," Journal of Theoretical Biology, vol. 235, no. 3, pp. 408-418, 2005.

[92] C. T. Rubin and K. J. McLeod, "Biologic modulation of mechanical influences in bone remodeling," in Biomechanics of Diarthrodial Joints, V. C. Mow, A. Ratcliff, and S. L.-Y. Woo, Eds., pp. 97-118, Springer, New York, NY, USA, 1990.

[93] C. T. Rubin, K. J. McLeod, and S. D. Bain, "Functional strains and cortical bone adaptation: epigenetic assurance of skeletal integrity," Journal of Biomechanics, vol. 23, supplement 1, pp. 43-54, 1990.

[94] R. D. Kent, "The uniqueness of speech among motor systems," Clinical Linguistics and Phonetics, vol. 18, no. 6-8, pp. 495-505, 2004.

[95] C. Rubin, S. Judex, and Y. X. Qin, "Low-level mechanical signals and their potential as a non-pharmacological intervention for osteoporosis," Age and Ageing, vol. 35, no. 2, pp. ii32-ii36, 2006.

[96] T. M. Cole, "Postnatal heterochrony of the masticatory apparatus in Cebus apella and Cebus albifrons," Journal of Human Evolution, vol. 23, no. 3, pp. 253-282, 1992.

[97] O. M. Pearson and D. E. Lieberman, "The aging of Wolff's "law": ontogeny and responses to mechanical loading in cortical bone," American Journal of Physical Anthropology, vol. 39, pp. 63-99, 2004.

[98] S. McBrearty and A. S. Brooks, "The revolution that wasn't: a new interpretation of the origin of modern human behavior," Journal of Human Evolution, vol. 39, no. 5, pp. 453-563, 2000. 
[99] F. E. Grine and D. J. Daegling, "New mandible of Paranthropus robustus from Member 1, Swartkrans Formation, South Africa," Journal of Human Evolution, vol. 24, no. 4, pp. 319$333,1993$.

[100] P. Brown and T. Maeda, "Liang Bua Homo floresiensis mandibles and mandibular teeth: a contribution to the comparative morphology of a new hominin species," Journal of Human Evolution, vol. 57, no. 5, pp. 571-596, 2009.

[101] J. L. Thompson and B. Illerhaus, "A new reconstruction of the Le Moustier 1 skull and investigation of internal structures using 3-D $\mu \mathrm{CT}$ data," Journal of Human Evolution, vol. 35, no. 6, pp. 647-665, 1998.

[102] P. Bayle, J. Braga, A. Mazurier, and R. Macchiarelli, "Dental developmental pattern of the Neanderthal child from Roc de Marsal: a high-resolution 3D analysis," Journal of Human Evolution, vol. 56, no. 1, pp. 66-75, 2009.

[103] J. Zilhau, D. E. Angelucci, E. Badal-Garcia et al., "Symbolic use of marine shells and mineral pigments by Iberian Neanderthals," Proceedings of the National Academy of Sciences of the United States of America, vol. 107, no. 3, pp. 1023-1028, 2010.

[104] B. Demes, J. T. Stern Jr., M. R. Hausman, S. G. Larson, K. J. Mcleod, and C. T. Rubin, "Patterns of strain in the macaque ulna during functional activity," American Journal of Physical Anthropology, vol. 106, no. 1, pp. 87-100, 1998.

[105] B. Demes, Y. X. Qin, J. T. Stern Jr., S. G. Larson, and C. T. Rubin, "Patterns of strain in the macaque tibia during functional activity," American Journal of Physical Anthropology, vol. 116, no. 4, pp. 257-265, 2001.

[106] D. E. Lieberman, J. D. Polk, and B. Demes, "Predicting Long Bone Loading from Cross-Sectional Geometry," American Journal of Physical Anthropology, vol. 123, no. 2, pp. 156-171, 2004. 


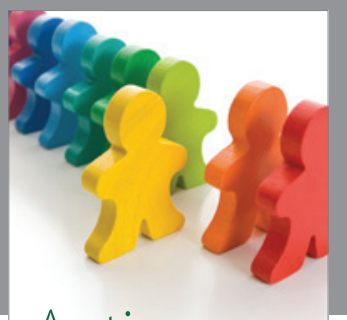

Autism

Research and Treatment
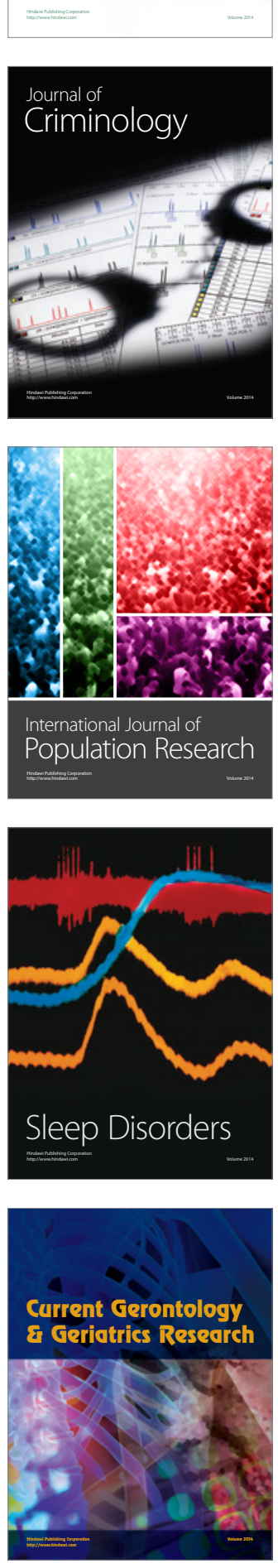
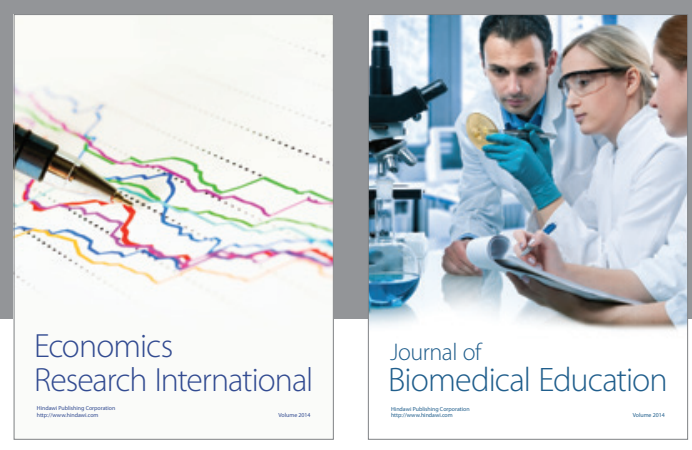

Journal of

Biomedical Education

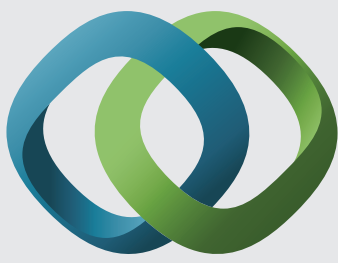

\section{Hindawi}

Submit your manuscripts at

http://www.hindawi.com
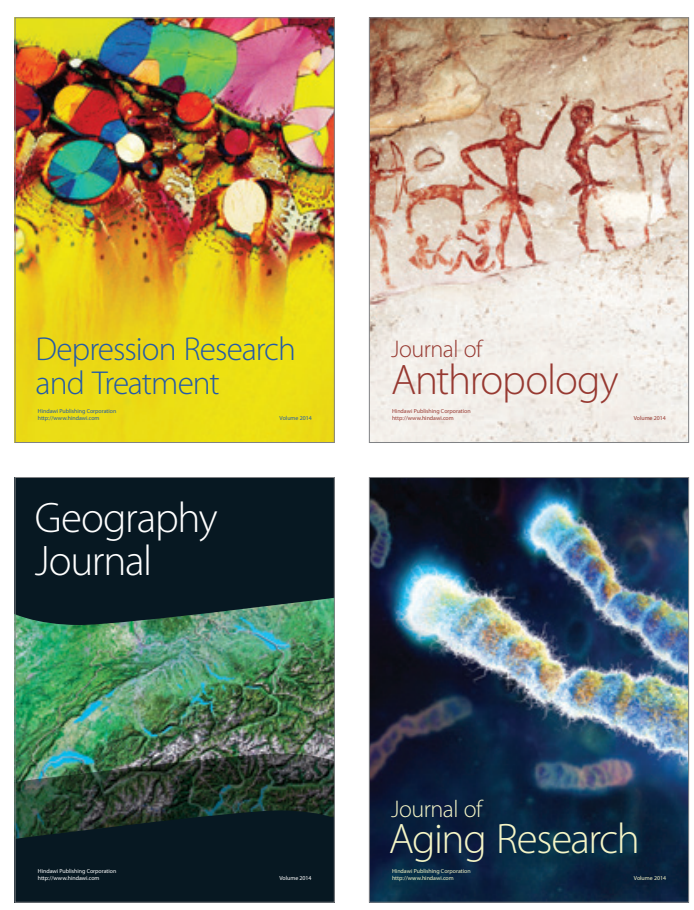

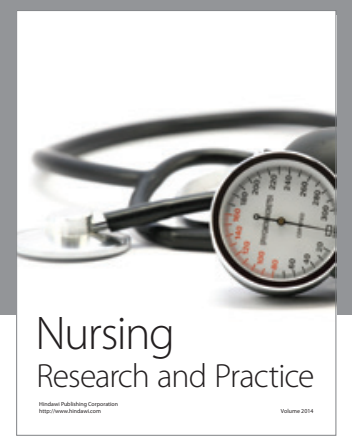

Nursing

Research and Practice

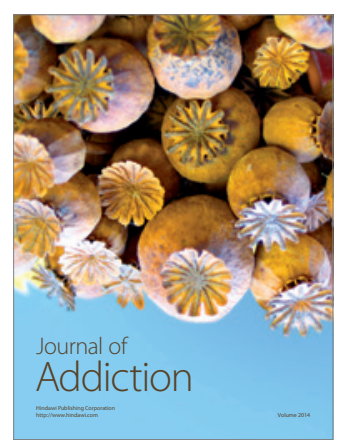

Child Development

Research

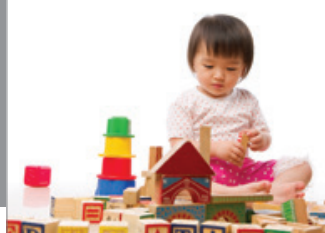

迥
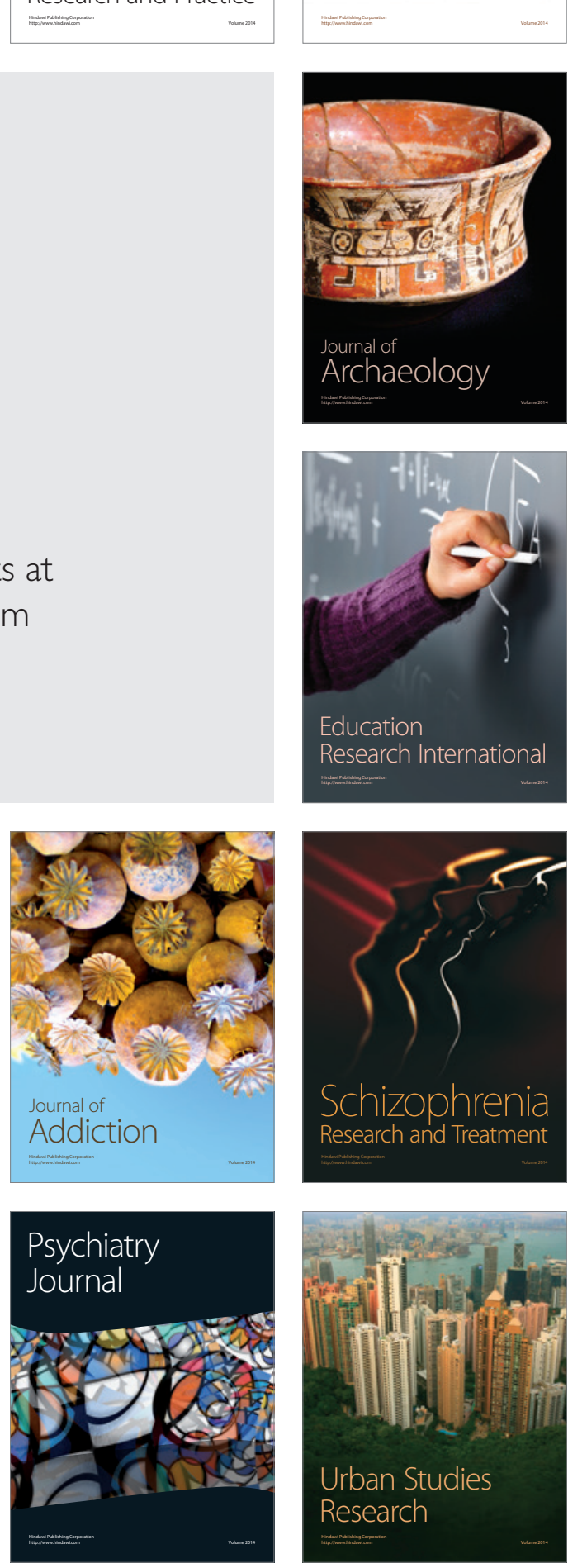